\title{
Margherita Cannavacciuolo: El cuerpo cómplice. Los cuentos de Julio Cortázar. Madrid: Visor Libros, 2020.
}

En las últimas décadas se ha experimentado un crecimiento considerable en el estudio de la representación del cuerpo en diferentes manifestaciones artísticas y culturales, y de forma paralela se ha creado - y para hoy se ha consolidado — un ámbito interdisciplinario cada vez más amplio que no solo permite estudiar obras y fenómenos contemporáneos, sino también revisar y revisitar autores y artistas canónicos. A partir de perspectivas teóricas tan diversas como los estudios estéticos, culturales, psicológicos, intermediales, filosóficos o antropológicos se aspira lograr una reestructuración de nuestros conocimientos fundamentales sobre el cuerpo — seguido por la revisión de otros términos afines, como sujeto e identidad—, postura también aplicada por la crítica literaria que examina diacrónicamente escritores sobre quienes, se suele decir, ya se ha escrito todo. Así es el caso del monográfico de Margherita Cannavacciuolo, docente de literaturas hispanoamericanas en la Universidad Ca' Foscari de Venecia, quien en El cuerpo cómplice pretende ofrecer una nueva aproximación a la cuentística cortazariana, centrándose en las representaciones del cuerpo de sus personajes, "punto de arranque de los mecanismos narrativos en los que la transgresión fantástica se articula" (19).

La pregunta clave que plantea la investigadora es cómo participa el cuerpo en la lógica fantástica. Para responder a la interrogativa, no solo estudia los relatos del autor, sino también rastrea sus ensayos, entrevistas y discursos, buscando referencias a la corporalidad, que no solo es un tema presente ya antes de su exilio parisino, sino también una cuestión prontamente planteada por la crítica que se dedica a estudiar su obra. La autora del monográfico logra demostrar que el cuerpo cobra valor narratológico y simbólico desde la cuentística temprana de Cortázar, abriéndose hacia una dialéctica enraizada en la carne como lugar de experiencias y situaciones reales o realistas en las que irrumpe lo fantástico: "la dialéctica envuelve el personaje a partir de su propio cuerpo. Este se convierte, por lo tanto, en el punto de arraigo de un doble conflicto, que se juega tanto entre el personaje y su entorno como dentro del mismo personaje" (39). Como también plantea Rafael Olea Franco en su prólogo al libro, Cannavacciuolo propone la hipótesis novedosa de que el cuerpo es el eje nodal para la construcción de lo fantástico cortazariano.

Vale la pena detenernos por un momento, para reunir las diferentes propiedades que adopta el cuerpo en los relatos de Cortázar. Según la autora, se trata de un elemento intermedio que "se sitúa entre los dos órdenes ontológicos inconciliables que conforman la estructura del relato fantástico, a la vez que se convierte en instancia de mediación entre el paradigma de realidad a partir del cual el texto se construye y el elemento fantástico que lo subvierte" (20). Como el cuerpo es el punto de fricción a través del cual se deja entrever la ambigüedad fantástica, el personaje siempre se concibe como sujeto fronterizo, capaz de tomar parte tanto en el paradigma realista como en el fantástico, de modo que su cuerpo viene a ser el lugar del intercambio simbólico entre los distintos niveles de la realidad: "se convierte en la frontera donde se soslaya y se anuncia el mecanismo fantástico, donde la otredad aflora en la oscuridad desentrañable de la realidad para manifestarse como indecible" (21). El sujeto, privado su cuerpo por el elemento fantástico, experimenta una fractura o disyunción, ya que la carne se convierte en "infralengua que traduce un código (realista) en otro (fantástico)" (44). De ahí se 
cristaliza el significado del título del presente tomo: "cómplice" no solo es una palabra que la autora toma prestada del propio Cortázar (de su idea del lector cómplice), sino también refleja la escisión que sufren sus personajes tras la "apertura" de su cuerpo, "frontera permeable entre el personaje y su entorno, [...] [que] se hace penetrable por la otredad fantástica" (43).

Para arrojar nueva luz sobre los cuentos del autor argentino, Cannavacciuolo no deja de lado las teorías de lo fantástico y la crítica cortazariana al respecto, sino las logra conjugar con las teorías sobre el sujeto y el cuerpo, de la percepción y la fenomenología husserliana y merleau-pontiana. Presta la metodología de análisis de la última: la investigadora aborda el cuerpo desde una perspectiva claramente fenomenológica cuando lo entiende no solo como algo indiferenciable del sujeto sino también como su vínculo principal con la realidad. Logra demostrar que el cuerpo mantiene una relación dialéctica con la alteración de su realidad: lo sufre y, a la vez, participa en ella. Por eso es que, en vez de "ambigüedad", la autora prefiere - siguiendo al pie la reflexión de Umberto Galimberti- hablar de "ambivalencia", en tanto "apertura de sentido que el cuerpo recobra y que sustituye la metafísica de la equivalencia" (45). Aplicando el concepto al cuerpo de los personajes cortazarianos, demuestra que "esta divide en dos la identidad, pero no para reconstruirla [...], sino para dejar vivir y subrayar la relación de tensión" (45). Es en este punto donde se encuentra la fenomenología con lo fantástico: en su tensión dialéctica, el cuerpo se sitúa entre lo conocido y lo desconocido, entre el paradigma real y el fantástico, y así, el sujeto queda desposeído de su cuerpo para abandonarse a una identidad múltiple y cambiante.

Según la investigadora, en esta ambivalencia se arraiga uno de los motivos mejor estudiados por la crítica: el del doble, tema principal del segundo capítulo que lleva como título "De máscaras y palimpsestos", donde se demuestra cómo el cuerpo será el puente o lugar de encuentro entre lo real y lo fantástico. Estudiando minuciosamente "Lejana", Cannavacciuolo logra evidenciar que el palíndromo y el anagrama son lingüísticamente lo que el abrazo es corporalmente: al fin y al cabo, el tacto físico es una metáfora en la cual se ficcionaliza y se realiza el juego verbal practicado por la protagonista. Analizando los relatos "Axolotl", "La noche boca arriba" y "Cambio de luces", igualmente se argumenta que el cuerpo sirve como una suerte de hilo de Ariadna entre los dos planos de realidad. Y si el cuerpo es lengua, serán significativos sus gestos, que bien pueden constituir un sistema expresivo propio que se abre a la posibilidad de expresar otro relato. En este sentido, el tema del doble no solo se trabaja a nivel somático, sino la corporalidad también atribuye a realizar el doble sentido: la gestualidad corpórea (analizada principalmente en "La salud de los enfermos", "Instrucciones para John Howell", "Silvia" y "Pesadilla") arroja luz sobre la ineficacia del lenguaje verbal, y así, del quiebre entre lo comunicado por las palabras y lo somáticamente sugerido.

El tercer capítulo, "Conflictos y alianzas", explora el papel que desempeñan los ojos (la mirada), las manos y los orificios del cuerpo (la oreja y la boca) en la narrativa breve de Cortázar. La investigadora italiana examina el papel hermenéutico pero también subversivo de la mirada y las manos — obsesión temática bien conocida del autor — en la constitución de lo fantástico, subrayando su importancia en vehicular la ambigüedad fantástica. El análisis minucioso de "Silvia", "Ómnibus", "Axolotl" y "Las babas del diablo" nos lleva a entender que, en estos relatos, la mirada no solo posibilita la transfusión identitaria —es decir, no solo es puente entre los diferentes niveles de la realidad textual-, sino también se propone como otra vía de conocer "la inabarcabilidad cognoscitiva" (168) que supone lo fantástico. Los 
estudios igualmente revelan el potencial simbólico de la mano desprendida de la voluntad del sujeto, que a menudo entra en relación dialéctica con la mirada. Para citar un solo ejemplo, el relato "Cuello de gato negro" presenta el involucramiento de las manos autónomas, a raíz de lo cual la mirada otorga su papel hermenéutico a la mano. En lo que se refiere a los cuentos donde se subraya la importancia de las orejas y la boca ("Cefalea", "La puerta condenada", "Las armas secretas" y "Las ménades"), Cannavacciuolo destaca la fragilidad ontológica de los límites del cuerpo: los orificios son aperturas hacia el mundo, lugares donde el adentro se enfrenta y se encuentra con el elemento fantástico que al mismo tiempo irrumpe en su realidad cotidiana.

El cuarto y último capítulo, "Vacíos", examina las diversas formas del silencio no resuelto, considerando este como base de la narrativa breve de Cortázar. El estado de desconocimiento y la ausencia de ciertos personajes alimentan la inquietud fantástica (también en el lector), y así, la ausencia viene a ser presencia marcada. En el primer apartado del capítulo, la investigadora ofrece un análisis bien fundamentado de "Cartas de mamá", "La salud de los enfermos" y "La autopista del sur", revelando que la ausencia material del cuerpo y el vacío creado por la muerte de los personajes de ninguna manera significa que estos dejen de existir: al contrario, siguen siendo actuantes que mantienen relaciones con los demás. Con otras palabras, son presencias justo debido a su propia ausencia y el ocultamiento forzado de parte de los demás personajes. El segundo apartado del capítulo es la otra cara del anterior: Cannavacciuolo analiza relatos (sobre todo se enfoca en "Las babas del diablo" y "Graffiti") donde la ausencia del cuerpo se compensa con la voz narrativa del sujeto. Es decir, se trata de cuentos donde la palabra cubre la ausencia del cuerpo, de manera que la voz "descorporeizada" se convierte en una presencia: una donde el sujeto — la otredad fantástica en sí- es capaz de manifestarse.

El cuerpo cómplice es una monografía lógicamente estructurada, cuya autora logra arrojar nueva luz sobre la lógica de construcción de los relatos cortazarianos. Gracias a los tres apartados temáticos que exploran, respectivamente, el tema del doble, la percepción y la ausencia como motivos recurrentes en las obras de Julio Cortázar, el lector tiene la posibilidad de estudiar la cuentística del autor desde ángulos diversos y hasta ahora no o solo parcialmente planteados por la crítica. Es más, la introducción teórica sobre el cuerpo entendido como cómplice en la constitución de lo fantástico cortazariano reviste de gran interés por la posibilidad de aplicarlo como metodología para estudiar la obra de otros autores que se dedican al género.

Petra Báder

Universidad Eötvös Loránd, Budapest bader.petra@btk.elte.hu

DOI: $\underline{\text { https://doi.org/10.24029/1ejana.2022.15.3563 }}$

Recibido: el 15 de enero de 2022

Aceptado: el 15 de febrero de 2022

Publicado: el 25 de febrero de 2022 
(C) Petra Báder

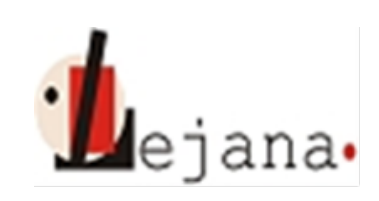

http://ojs.elte.hu/index.php/lejana

Universidad Eötvös Loránd, Departamento de Español, 1088 Budapest, Múzeum krt. 4/C 